\section{Bioconjugation of quantum dot luminescent probes for Western blot analysis}

\author{
Savvas C. Makrides, Christina Gasbarro, and Job M. Bello \\ EIC Laboratories, Inc., Norwood, MA, USA \\ BioTechniques 39:501-506 (October 2005) \\ doi 10.2144/000112004
}

\begin{abstract}
Western blot analysis is a widely used technique for protein immunodetection. Its current format, however, is unsuitable for multiplex detection of proteins, primarily due to intrinsic limitations of standard organic dyes employed as probes. Quantum dot (QD) semiconductor nanoparticles exhibit significant advantages over organic dyes, including their broad absorption bands, narrow, tunable, and symmetric emission spectra, large Stokes shifts, and excellent photostability. Here we describe a novel method for the functionalization of streptavidin-coated $Q D s$ with an in vivo biotinylated peptide (head-to-tail dimerized $Z$ domain derived from protein A) that permits the facile conjugation of antibodies to QDs. In this study, we demonstrate the simultaneous detection of two different types of protein in a Western blot. The bioconjugation of QDs described here makes it possible to achieve multiplex detection of proteins in Western blot analysis in a more straightforward manner.
\end{abstract}

\section{INTRODUCTION}

Western blot analysis $(1,2)$ is one of the most widely used methods for analyzing specific protein targets using colorimetric or chemiluminescent substrates (3). However, the reporting labels that are typically used for protein detection are unsuitable for simultaneous detection of multiple targets. In order to detect different proteins, the blot is usually stripped and reprobed, an approach that is time- and laborintensive and often leads to the loss of immobilized proteins from the blot. Detection of multiple antigens on a single protein blot without stripping off prior antibodies is possible but requires sequential reactions (4). More recent approaches employ multiple fluorescent probes made from small organic dye molecules (Reference 5 and references therein), but such probes have several limitations. The use of quantum dot (QD) luminescent labels has the potential to eliminate most of these problems.

QDs are semiconductor nanoparticles (e.g., CdSe, InP, InAs) with diameters in the range of $2-10 \mathrm{~nm}$ whose fundamental physical properties are influenced by quantum confinement effects (6). QDs exhibit absorption and emission peaks that progressively shift to longer wavelengths with increasing particle size. QDs have significant advantages compared to standard fluorescent organic dyes. For example, dyes have narrow absorption bands, thus it is difficult to excite several colors with a single excitation source. Moreover, the broad spectral overlap between the emissions of dyes requires complex mathematical analysis of the data. In contrast, QDs have a narrow, tunable, symmetric emission spectrum, permitting a larger number of probes within a detectable spectral region. Different size populations of QDs can be excited with a single light source, making possible the development of simpler and more cost-effective instrumentation for multiplex detection of biomolecules. QDs are considerably more stable against photobleaching than organic dyes $(7,8)$. This is an important property, particularly for imaging applications, where the high photostability of QDs allows real-time monitoring of intracellular processes over longer periods of time $(9,10)$. QDs exhibit large Stokes shifts (the difference between the maximum absorbance and emission wavelengths), and this property allows the target signals to be separated clearly from autofluorescence and enables the entire emission spectra to be collected, in contrast to the use of fluorescent proteins, such as green fluorescent protein. The biological applications of QDs have been recently reviewed $(11,12)$.

Here we describe a novel bioconjugation method that permits the facile generation of QD-based probes for multiplex detection of proteins in Western blots. Our strategy for immobilization of antibodies to QDs utilizes the immunoglobulin $\mathrm{G}(\operatorname{IgG})$ binding $\mathrm{Z}$ domain, which is based on the B domain of Staphylococcus aureus protein $\mathrm{A}(13,14)$. The $\mathrm{Z}$ affinity tag $(6.5 \mathrm{kDa})$ is highly specific for its ligand, $\operatorname{IgG~Fc}$, and can easily be purified by affinity chromatography using $\mathrm{IgG}-$ Sepharose ${ }^{\circledR}$. It has been previously shown (15) that the divalent ZZ domain exhibits 10 times higher affinity $\left(\mathrm{K}_{\mathrm{aff}} \sim 3 \times 10^{8} \mathrm{M}^{-1}\right)$ for its $\mathrm{IgG}$ ligand than the monovalent $\mathrm{Z}$ domain $\left(K_{\text {aff }} \sim 2 \times 10^{7} \mathrm{M}^{-1}\right)$. We engineered a $\mathrm{ZZ}$ protein fused to a peptide that is biotinylated in vivo (16), followed by a

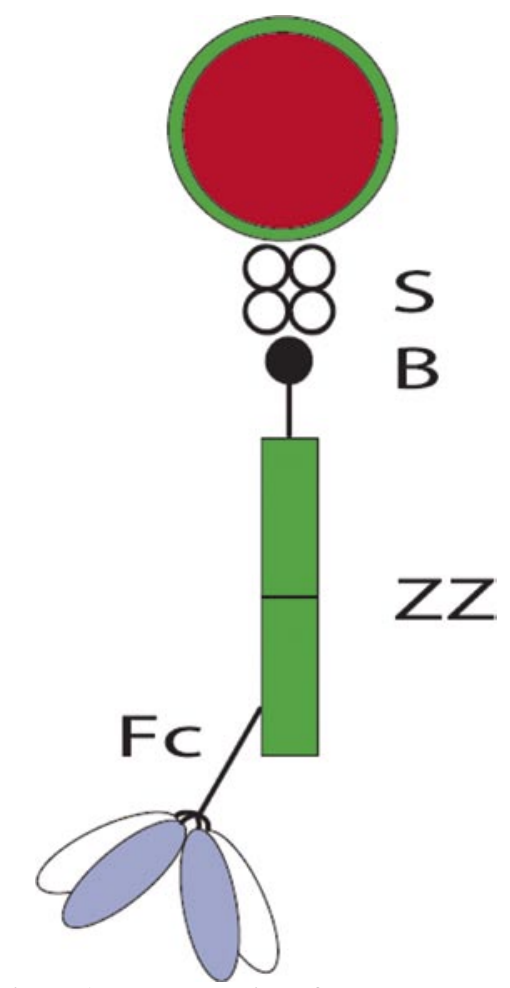

Figure 1. Representation of the quantum dotbased probe. There are approximately $5-10$ streptavidin molecules on the quantum dot (QD) surface. S, streptavidin; B, biotin; ZZ, head-totail dimerized $\mathrm{Z}$ domain derived from protein A. A hexahistidine tag (not shown) is located at the $\mathrm{C}$ terminus of the $\mathrm{ZZ}$ tag. The various probe components are not drawn to scale. 
hexahistidine tag. The biotinylated $\mathrm{ZZ}$ tag was produced in bacteria, purified on a monomeric avidin or $\mathrm{Ni}^{2+}$-NTA matrix, and coupled to streptavidincoated QDs, thus enabling biospecific conjugation of any antibody to the functionalized QDs (Figure 1). The advantages of our probe are discussed.

\section{MATERIALS AND METHODS}

\section{Construction of pEZZ-B6H}

The phagemid pEZZ18 (Amersham Biosciences, Piscataway, NJ, USA) contains the protein A signal sequence (S), two $\mathrm{Z}$ domains, and a polylinker site located $3^{\prime}$ to the ZZ domain (14). Expression is controlled by the protein A constitutive promoter. The polylinker of pEZZ18 was digested with EcoRI and $P s t \mathrm{I}$, and the large vector fragment was purified from a $0.8 \%$ agarose gel in TAE buffer $(40 \mathrm{mM}$ Tris, 5 $\mathrm{mM}$ sodium acetate, $1 \mathrm{mM}$ EDTA, pH 7.8) using the GeneClean ${ }^{\circledR}$ II Kit (Qbiogene, Irvine, CA, USA). Two synthetic complementary oligonucleotides (Qiagen, Valencia, CA, USA), 115 and 107 bases long, respectively, were designed to encode the in vivo biotinylation signal sequence (16) and six histidine residues followed by two stop codons, including sequences to regenerate the EcoRI, BamHI, and PstI restriction sites (underlined): 5'-AATT CGGGCAGCGCGAGCAGCCTGCG CCAGATTCTGGATAGCCAGAAAA TTGAATGGCGCAGCAACGCGGG CGGCAGCGGCCATCATCATCATC ATCATTAATAAGGATCCTGCA-3' and $5^{\prime}$-GGATCCTTATTAATGATGA TGATGATGATGGCCGCTGCCGC CCGCGTTGCTGCGCCATTCAAT TTTCTGGCTATCCAGAATCTGGC GCAGGCTGCTCGCGCTGCCCG$3^{\prime}$. This DNA sequence was designed using the codon usage frequency for Escherichia coli K12 (Codon Usage Database, www.kazusa.or.jp/codon). The oligonucleotides were separately resuspended in $10 \mathrm{mM}$ Tris- $\mathrm{HCl}, \mathrm{pH}$ $8.0,10 \mathrm{mM} \mathrm{NaCl}$, and annealed by mixing equimolar amounts and heating to $100^{\circ} \mathrm{C}$ followed by slow cooling to $22^{\circ} \mathrm{C}$. The linearized vector was ligated to the double-stranded oligonucleotide using the Rapid DNA Ligation Kit
(Roche Applied Science, Indianapolis, IN, USA). The resulting plasmid pEZZ-B6H (Figure 2) was transformed into $E$. coli BL21 competent cells (Novagen, Madison, WI, USA), and the plasmid was prepared using a HiSpeed Plasmid Maxi Kit (Qiagen). The plasmid was also transformed into AVB101 competent cells (Avidity, Denver, CO, USA), which harbor a chloramphenicol-resistant plasmid pJS169 encoding the BirA biotin ligase gene.

\section{Expression}

E. coli AVB101 cells harboring plasmids pJS169 and pEZZ-B6H were grown to $\mathrm{A}_{600}$ of 0.5 in $250 \mathrm{~mL}$ Luria Bertani (LB) medium containing 100 $\mu \mathrm{g} / \mathrm{mL}$ ampicillin and $10 \mu \mathrm{g} / \mathrm{mL}$ chloramphenicol in baffled flasks at $37^{\circ} \mathrm{C}$ at $90 \mathrm{rpm}$. The medium was then supplemented with $50 \mu \mathrm{M}$ biotin and $1 \mathrm{mM}$ isopropyl $\beta$-D-thiogalactopyranoside (IPTG) in order to induce the expression of the birA gene. The cells were grown for an additional $5 \mathrm{~h}$.

\section{Protein Extraction and Purification}

The cells were harvested by centrifugation at $5000 \times \mathrm{g}$ for $15 \mathrm{~min}$ at $4^{\circ} \mathrm{C}$, and the $\mathrm{ZZ}$ tag (molecular weight: approximately 17,000 ) was extracted from the periplasm by the osmotic shock procedure (17), which was modified as follows. The cell pellet was resuspended in $1 / 20$ original culture volume of ice-cold sucrose buffer $(0.5$ M sucrose, $0.1 \mathrm{M}$ Tris-HCl, $\mathrm{pH}$ 8.0, 1 mM EDTA). Phenylmethylsulfonyl fluoride (PMSF) was added to a $1-\mathrm{mM}$ final concentration, and the suspension was stirred slowly at room temperature for $10 \mathrm{~min}$. The cells were collected by centrifugation at $15,000 \times g$ for $10 \mathrm{~min}$ at $4{ }^{\circ} \mathrm{C}$. The cell pellet was resuspended in $12 \mathrm{~mL}$ ice-cold $5 \mathrm{mM} \mathrm{MgSO}_{4}$ and stirred slowly for $10 \mathrm{~min}$ at $4^{\circ} \mathrm{C}$. The shocked cells were centrifuged at $15,000 \times g$ for $10 \mathrm{~min}$ at $4^{\circ} \mathrm{C}$, and the supernatant was filtered through a $0.45-\mu \mathrm{m}$ nitrocellulose membrane filter (Nalge Nunc International, Rochester, NY, USA).

The ZZ tag was purified on a monomeric avidin column (part of the Immobilized Monomeric Avidin Kit; Pierce Biotechnology, Rockford, IL, USA) using $2 \mathrm{mM}$ biotin in phosphate-buffered saline (PBS) for elution. Protein fractions identified by polyacrylamide gel electrophoresis (PAGE) and Western blot analysis were pooled and dialyzed at $4^{\circ} \mathrm{C}$ in Slide-A-Lyzer ${ }^{\circledR}$ Cassettes (Pierce Biotechnology) against three changes of PBS. The concentration of the $\mathrm{ZZ}$ peptide was determined using the BCA ${ }^{\mathrm{TM}}$ Protein Assay (Pierce Biotechnology) and bovine serum albumin (BSA) as the standard. Alternatively, the ZZ was purified on an agarose- $\mathrm{Ni}^{2+}$-NTA chromatography column (Qiagen). The osmotic shock

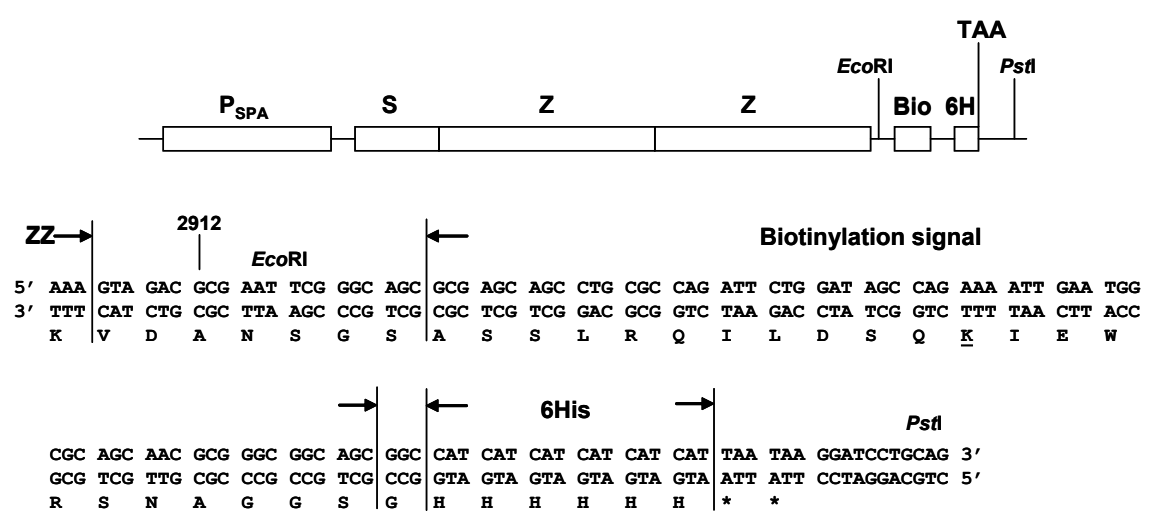

Figure 2. Configuration and DNA sequence of selected genetic elements in vector pEZZ-B6H for production of the $\mathbf{Z Z}$ tag in Escherichia coli. $\mathrm{P}_{\mathrm{SPA}}$, promoter of the staphylococcal protein A; $\mathrm{S}$, signal peptide; $\mathrm{ZZ}$, immunoglobulin $\mathrm{G}$ ( $\mathrm{IgG}$ )-binding dimeric domain derived from protein $\mathrm{A}$; Bio, in vivo biotinylation tag; $6 \mathrm{H}$, hexahistidine tag; TAA $(*)$, termination codon. The boundaries of the ZZ moiety, the biotinylation, and hexahistidine tags are shown, and the single lysine residue (K) that is biotinylated is underlined. The number 2912 refers to the nucleotide position in the parental plasmid pEZZ18 (GeneBank ${ }^{\circledR}$ accession no. M74186). 
supernatant $(12 \mathrm{~mL})$ was loaded onto 4 $\mathrm{mL} \mathrm{Ni}{ }^{2+}$-NTA resin (Qiagen) that was equilibrated with $40 \mathrm{~mL}$ wash buffer (50 $\mathrm{mM} \mathrm{NaH}_{2} \mathrm{PO}_{4}, 300 \mathrm{mM} \mathrm{NaCl}, 20$ mM imidazole, $\mathrm{pH} 8.0$ ), and the $\mathrm{ZZ}$ was eluted using $20 \mathrm{~mL}$ elution buffer (50 $\mathrm{mM} \mathrm{NaH}_{2} \mathrm{PO}_{4}, 300 \mathrm{mM} \mathrm{NaCl}, 250 \mathrm{mM}$ imidazole, $\mathrm{pH} 8.0)$. Fractions $(1.5 \mathrm{~mL})$ were analyzed by PAGE and Western blot analysis. Fractions of interest were pooled and concentrated in PBS via repeated centrifugation $(5000 \times g$ for $30 \mathrm{~min}$ in a fixed angle rotor) using Amicon ${ }^{\circledR}$ Ultra-15 Centrifugal Filter devices [5000 nominal molecular weight limit (NMWL); Millipore, Bedford, MA, USA].

\section{Western Blot Analysis of the $\mathrm{ZZ}$ Protein}

ZZ samples (18 $\mu \mathrm{L}$, approximately $2 \mu \mathrm{g}$ ) were prepared in $1 \times$ LDS Sample Buffer (Invitrogen, Carlsbad, CA, USA) in a total volume of $25 \mu \mathrm{L}$, incubated at $70^{\circ} \mathrm{C}$ for $10 \mathrm{~min}$, loaded

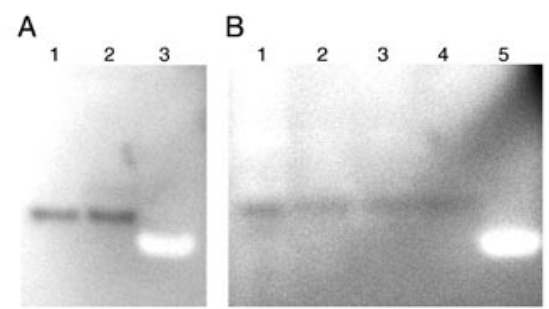

Figure 3. Western blots of different batches of biotinylated $\mathrm{ZZ}$ peptide purified using (A) monomeric avidin or $(B) \mathrm{Ni}^{2+}$-NTA matrix. (A) Lanes 3 and (B) 5 contain lysozyme as a negative control.

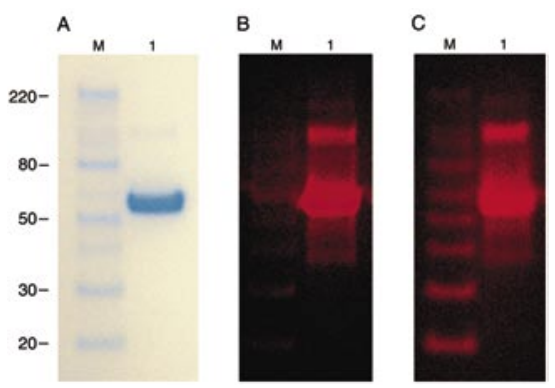

Figure 4. Western blots of luciferase using quantum dot-based probes. (A) Polyacrylamide gel electrophoresis (PAGE). (B and C) Western blot analysis using (B) primary antibody alone or (C) primary and secondary antibodies. The upper band (approximately $124 \mathrm{kDa}$ ) is believed to be dimerized luciferase. Control blots were probed with quantum dot (QD)-ZZ probes minus antibody (not shown). M, markers (MagicMark ${ }^{\mathrm{TM}}$; Invitrogen); 1, luciferase, 62,000 molecular weight. The markers contain an immunoglobulin $\mathrm{G}$ (IgG)-binding site. onto $4 \%-12 \%$ NuPAGE $^{\circledR}$ Bis-Tris gels, and electrophoresed at $200 \mathrm{~V}$ in $1 \times$ MES buffer (both from Invitrogen) under nonreducing conditions. The gels were stained by immersing in Simply Blue ${ }^{\mathrm{TM}}$ SafeStain (Invitrogen) for $60 \mathrm{~min}$ and destained in water. The protein bands were electrotransferred to polyvinylidene difluoride (PVDF) membranes (Immobilon-P; Millipore) using the model HEP-1 PantherTM Semidry Electroblotter and buffer reagents according to the manufacturer's instructions (Owl Separation Systems, Portsmouth, NH, USA). Transfer proceeded for $1 \mathrm{~h}$ at $1.6 \mathrm{~mA} /$ $\mathrm{cm}^{2}(100 \mathrm{~mA})$. After sandwich disassembly, the membrane was incubated in SuperBlock ${ }^{\mathrm{TM}}$ blocking buffer (Pierce Biotechnology) for $1 \mathrm{~h}$ at $22^{\circ} \mathrm{C}$ with gentle agitation or stored in blocking buffer overnight at $4^{\circ} \mathrm{C}$. The gel was stained to confirm protein transfer. The membrane was then incubated for $2 \mathrm{~h}$ in blocking buffer containing a 1:1000 dilution of avidin-alkaline phosphatase (AP) conjugate (Pierce Biotechnology) and washed three times for $10 \mathrm{~min}$ each with blocking buffer. The membrane was then incubated in NBT/BCIP substrate (Pierce Biotechnology) until bands indicating the presence of ZZ-bound avidin-AP were visible. The positive control lane contained $2 \mu \mathrm{g}$ biotinylated protein A (Pierce Biotechnology).

\section{QD Probe Assembly and Western Blots}

Streptavidin-coated $\mathrm{CdSe} / \mathrm{ZnS}$ core/shell QDs of different size and emission wavelength (Quantum Dot, Hayward, CA, USA) were coupled to primary antibodies via the $\mathrm{ZZ}$ tag, as follows: QD aliquots $(10-30 \mu \mathrm{L}$ of 1
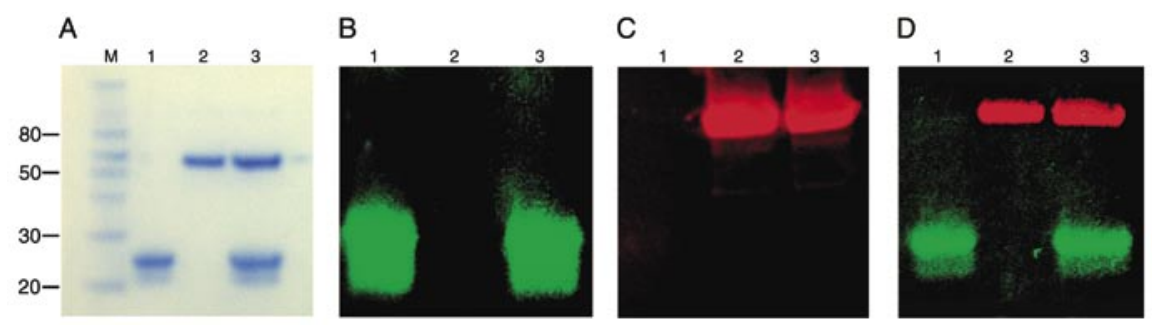

Figure 5. Western blots of apolipoprotein AI and luciferase. (A) PAGE. M, markers; 1, apoAI (28,330 molecular weight); 2, luciferase (62,000 molecular weight); 3, both proteins. (B) Western blot probed with anti-apoAI-QD ${ }_{565} ;(\mathrm{C})$ anti-luciferase-QD ${ }_{655} ;$ (D) anti-apoAI-QD ${ }_{565}$ plus anti-luciferase- $\mathrm{QD}_{655}$. Control blots were probed with QD-ZZ probes minus primary antibody (not shown). The Western blots were photographed separately, thus band migration appears to be different in different blots. 
blocking buffer [rabbit anti-apoAI (EMD Biosciences) and goat anti-luciferase (Rockland Immunochemicals, Gilbertsville, PA, USA)], washed with TBST three times for 5 min each, and incubated for 1 to $2 \mathrm{~h}$ with $\mathrm{QD}_{565}-\mathrm{ZZ}$ or $\mathrm{QD}_{655}-\mathrm{ZZ}$ nanoparticles conjugated to secondary antibody, and purified as described above. The blots were then sequentially washed three times for 5 min each using TBST and two times for $3 \mathrm{~min}$ each using Tris-buffered saline (TBS). Proteins were probed alone and in combination to confirm the specificity of each antibody. The negative-control Western blot was incubated in SuperBlock buffer without primary antibody. Protein bands were visualized under long-wavelength UV irradiation. Images were captured using a model A1 Minolta digital camera and merged into false-color images using the National Institutes of Health (NIH) Image J software (rsb.info.nih.gov/ij).

\section{RESULTS AND DISCUSSION}

Fusion proteins containing a specific biotinylation motif are biotinylated in vivo by biotin protein ligase, the product of the birA gene, which recognizes a 75-amino acid residue sequence as its biotinylation substrate (18). Such proteins can be affinity-purified using immobilized monomeric avidin and mild elution conditions that do not damage the biotinylated protein. This approach is advantageous over in vitro biotinylation, an indiscriminate process that may adversely affect the structure and/or function of the modified protein through the modification of critical lysine residues. Schatz (16) identified a consensus 13-residue peptide that is biotinylated in vivo at an invariant lysine residue. This sequence can replace the larger biotinylation signal and has been used successfully for the purification of fusion proteins (19). A potential disadvantage of the affinity chromatographic purification of in vivo biotinylated proteins is the need to remove free biotin from the cell lysate to avoid interference with the purification of the target protein. In addition, biotinylated host proteins may possibly be co-purified with the target protein. These potential complications are easily avoided by including an additional affinity tag that facilitates protein purification by an alternative method prior to the use of avidin-chromatographic media (20). We included a $\mathrm{His}_{6}$ tag located downstream of the biotinylation sequence to facilitate purification of the biotinylated $\mathrm{ZZ}$ using a $\mathrm{Ni}^{2+}$ NTA matrix. The ZZ tag was purified from $E$. coli using monomeric avidin as well as $\mathrm{Ni}^{2+}$-NTA, and analyzed on a Western blot probed with an avidinalkaline phosphatase conjugate. The results confirmed the presence of biotinylated $\mathrm{ZZ}$ protein, with no evidence of additional biotinylated bands, irrespective of the purification method (Figure 3).

In order to evaluate the sensitivity of protein detection using QDs, Western blots of luciferase were probed with QD-ZZ conjugates coupled directly to primary anti-luciferase antibodies (Figure 4B). In addition, QD-ZZ conjugates were coupled to secondary antibodies and used to probe blots that had already been probed with primary anti-luciferase antibodies (Figure 4C). The results indicate that somewhat greater sensitivity was achieved using both primary and secondary antibodies (Figure 4C), although the primary antibody alone (Figure 4B) produced excellent results. The bioconjugation scheme did not significantly alter the spectroscopic properties of the QDs; that is, both the emission wavelength and the quantum yield of the functionalized QDs remained unchanged (data not shown).

For the simultaneous detection of two different types of protein, Western blots of human apolipoprotein $\mathrm{AI}$ and firefly luciferase were first probed with primary antibodies followed by incubation with $\mathrm{QD}_{565^{-}} \mathrm{ZZ}$ or $\mathrm{QD}_{655^{-}}$ $\mathrm{ZZ}$ nanoparticles or both, conjugated to secondary antibodies. Both proteins were easily visualized on the same blot (Figure 5D).

In summary, we have demonstrated a new method of QD bioconjugation for the multiplex detection of proteins in Western blot analysis. A similar study has recently been published using a different QD bioconjugation methodology (R.L. Ornberg, T.F. Harper, and H. Liu, Application Note, Nat. Methods 2005, 2:79). The advan- tages of our probe are that the $\mathrm{ZZ}$ tagderivatized surface of QDs enables facile conjugation to secondary (or primary) antibodies, eliminates the labor and expense of custom-labeling secondary antibodies with different enzymes, biotin, and other tags, and avoids the potential nonavailability of secondary antibodies with the desired label. More important, the ZZ peptide does not bind the Fab region of immunoglobulin molecules, in contrast to all individual domains of protein $\mathrm{A}$ $(21,22)$. This offers the advantage of a more uniform binding to antibodies (via the $\mathrm{Fc}$ region), leaving the $\mathrm{Fab}$ domain free to bind its target, unlike direct QD-antibody binding, which sterically blocks many of the antibody active sites. Thus, our QD bioconjugation strategy could be useful for quantitative assays. The only requirement for specificity of protein detection in our system is the matching of primary and secondary antibodies. This too can be avoided by directly conjugating primary antibodies to ZZ-functionalized QDs, although, in this case, the sensitivity of detection is attenuated (Figure 4). The results obtained here will facilitate the further optimization of our system for the simultaneous detection of a greater number of proteins in Western blots. Ongoing work will address the use of a more efficient recognition sequence for in vivo biotinylation (23) and determine the concentration of biotinylated $\mathrm{ZZ}$ protein in order to optimize the QD:ZZ molar ratios for probe assembly.

\section{ACKNOWLEDGMENTS}

We are grateful to Per-Åke Nygren for advice on the ZZ protein throughout the course of this work and for critically reading the manuscript. We thank Theresa Harper of Quantum Dot Corporation for technical advice on QDs and Nancy Kawai for help with the figures. Funding of this work by the DOE (DE-FG02-04ER83933) is gratefully acknowledged. 


\section{COMPETING INTERESTS STATEMENT}

The authors declare no competing interests.

\section{REFERENCES}

1.Towbin, H., T. Staehelin, and J. Gordon. 1979. Electrophoretic transfer of proteins from polyacrylamide gels to nitrocellulose sheets: procedure and some applications. Proc. Natl. Acad. Sci. USA 76:4350-4354.

2.Renart, J., J. Reiser, and G.R. Stark. 1979. Transfer of proteins from gels to diazobenzyloxymethyl-paper and detection with antisera: a method for studying antibody specificity and antigen structure. Proc. Natl. Acad. Sci. USA 76:3116-3120.

3.Kurien, B.T. and R.H. Scofield. 2003. Protein blotting: a review. J. Immunol. Methods 274:1-15.

4.Krajewski, S., J.M. Zapata, and J.C. Reed. 1996. Detection of multiple antigens on Western blots. Anal. Biochem. 236:221-228.

5.Gingrich, J.C., D.R. Davis, and Q. Nguyen. 2000. Multiplex detection and quantitation of proteins on Western blots using fluorescent probes. BioTechniques 29:636-642.

6.Alivisatos, A.P. 1996. Semiconductor clusters, nanocrystals, and quantum dots. Science 271:933-937.

7.Chan, W.C.W. and S.M. Nie. 1998. Quantum dot bioconjugates for ultrasensitive nonisotopic detection. Science 281:2016-2018.

8.Wu, X., H. Liu, J. Liu, K.N. Haley, J.A. Treadway, J.P. Larson, N. Ge, F. Peale, and M.P. Bruchez. 2003. Immunofluorescent labeling of cancer marker Her2 and other cellular targets with semiconductor quantum dots. Nat. Biotechnol. 21:41-46.

9.Chan, W.C.W., D.J. Maxwell, X.H. Gao, R.E. Bailey, M.Y. Han, and S.M. Nie. 2002. Luminescent quantum dots for multiplexed biological detection and imaging. Curr. Opin. Biotechnol. 13:40-46.

10.Dubertret, B., P. Skourides, D.J. Norris, V. Noireaux, A.H. Brivanlou, and A. Libchaber. 2002. In vivo imaging of quantum dots encapsulated in phospholipid micelles. Science 298:1759-1762.

11.Alivisatos, P. 2004. The use of nanocrystals in biological detection. Nat. Biotechnol. 22:47-52.

12.Michalet, X., F.F. Pinaud, L.A. Bentolila, J.M. Tsay, S. Doose, J.J. Li, G. Sundaresan, A.M. Wu, et al. 2005. Quantum dots for live cells, in vivo imaging, and diagnostics. Science 307:538-544.

13.Nilsson, B., T. Moks, B. Jansson, L. Abrahmsen, A. Elmblad, E. Holmgren, C. Henrichson, T.A. Jones, and M. Uhlén. 1987. A synthetic IgG-binding domain based on Staphylococcal protein A. Protein Eng. 1:107-113.

14.Löwenadler, B., B. Jansson, S. Paleus, E. Holmgren, B. Nilsson, T. Moks, G. Palm, S. Josephson, et al. 1987. A gene fusion system for generating antibodies against short peptides. Gene 58:87-97.
15.Nilsson, J., P. Nilsson, Y. Williams, L. Pettersson, M. Uhlén, and P.-Å. Nygren. 1994. Competitive elution of protein A fusion proteins allows specific recovery under mild conditions. Eur. J. Biochem. 224:103-108.

16.Schatz, P.J. 1993. Use of peptide libraries to map the substrate specificity of a peptidemodifying enzyme: a 13 residue consensus peptide specifies biotinylation in Escherichia coli. Biotechnology (NY) 11:1138-1143.

17.Nossal, N.G. and L.A. Heppel. 1966. The release of enzymes by osmotic shock from Escherichia coli in exponential phase. J. Biol. Chem. 241:3055-3062.

18.Cronan, J.E., Jr. 1990. Biotination of proteins in vivo. A post-translational modification to label, purify, and study proteins. J. Biol. Chem. 265:10327-10333.

19.Nilsson, J., M. Larsson, S. Ståhl, P.-Å. Nygren, and M. Uhlén. 1996. Multiple affinity domains for the detection, purification and immobilization of recombinant proteins. J. Mol. Recognit. 9:585-594.

20.Nilsson, J., S. Ståhl, J. Lundeberg, M. Uhlén, and P.-Å. Nygren. 1997. Affinity fusion strategies for detection, purification, and immobilization of recombinant proteins. Protein Expr. Purif. 11:1-16.

21.Jansson, B., M. Uhlén, and P.-Å. Nygren. 1998. All individual domains of staphylococcal protein A show Fab binding. FEMS Immunol. Med. Microbiol. 20:69-78.

22.Graille, M., E.A. Stura, A.L. Corper, B.J. Sutton, M.J. Taussig, J.B. Charbonnier, and G.J. Silverman. 2000. Crystal structure of a Staphylococcus aureus protein A domain complexed with the Fab fragment of a human IgM antibody: structural basis for recognition of B-cell receptors and superantigen activity. Proc. Natl. Acad. Sci. USA 97:5399-5404.

23.Beckett, D., E. Kovaleva, and P.J. Schatz. 1999. A minimal peptide substrate in biotin holoenzyme synthetase-catalyzed biotinylation. Protein Sci. 8:921-929.

Received 18 February 2005; accepted 15 March 2005.

Address correspondence to Savvas C. Makrides, Shire Pharmaceuticals, 700 Main Street, Cambridge, MA 02139, USA. email: smakrides@tktx.com

\author{
To purchase reprints \\ of this article, contact \\ Reprints@BioTechniques.com
}

